\title{
Seed germination and seedling establishment of an invasive tropical tree species under different climate change scenarios
}

\begin{tabular}{|r|l|}
\hline Journal: & Austral Ecology \\
\hline Manuscript ID & Draft \\
\hline Manuscript Type: & Research Article \\
\hline Date Submitted by the & n/a \\
\hline Complete List of Authors: & $\begin{array}{l}\text { Tietze, Hedwig Selma Eugenia; Universidade Federal de Santa Catarina, } \\
\text { Programa de pós-graduação em Ecologia; Universitat Potsdam, } \\
\text { Biodiversity Research/Systematic Botany, Institute of Biochemistry and } \\
\text { Biology } \\
\text { Joshi, Jasmin; Universitat Potsdam, Biodiversity Research/Systematic } \\
\text { Botany, Institute of Biochemistry and Biology } \\
\text { Pugnaire, Francisco; Estación Experimental de Zonas Áridas, CSIC , } \\
\text { Ecologia Funcional y Evolutiva; } \\
\text { Dechoum, Michele; Federal University of Santa Catarina, of Ecology and } \\
\text { Zoology }\end{array}$ \\
\hline Keywords: & $\begin{array}{l}\text { Co2 concentration, coastal dunes, establishment, invasive plant, plant } \\
\text { invasion, Terminalia catappa, temperature }\end{array}$ \\
\hline
\end{tabular}

\section{SCHOLARONE Manuscripts}


1 Seed germination and seedling establishment of an invasive tropical tree species under different climate change scenarios

3

Hedwig Selma Eugenia Tietze ${ }^{1,2}$, Jasmin Joshi ${ }^{2,4,5}$, Francisco Ignacio Pugnaire ${ }^{3}$, Michele de

5 Sá Dechoum ${ }^{1 *}$

6

$7 \quad{ }^{1}$ Programa de pós-graduação em Ecologia, Universidade Federal de Santa Catarina, Campus

Universitário s/n - Córrego Grande, Florianópolis, SC 88040-900, Brazil.

${ }^{2}$ Biodiversity Research/Systematic Botany, Institute of Biochemistry and Biology, University of Potsdam, Germany.

${ }^{3}$ Estación Experimental de Zonas Áridas, Consejo Superior de Investigaciones Científicas (EEZA-CSIC), Ctra. Sacramento s/n, La Cañada, E-04120 Almería, Spain.

${ }^{4}$ Berlin-Brandenburg Institute of Advanced Biodiversity Research (BBIB), 14195 Berlin, Germany, Altensteinstr. 6, 14195 Berlin, Germany.

${ }^{5}$ Hochschule für Technik HSR Rapperswil, Institute for Landscape and Open Space, Seestrasse 10, 8640 Rapperswil, Switzerland

* Corresponding author: mdechoum@gmail.com; Telephone number: (+5548) 3304-2856

\section{Acknowledgements}

We thank Dr. Paulo Horta, Dr. Karla Scherer, Alexandre Schmidt and Lucas Machado for assistance in the installation and maintenance of the experimental setup, and two anonymous reviewers who provided valuable comments on an earlier draft of this manuscript. This work was supported by the Coordenação de Aperfeiçoamento de Pessoal de Nível Superior/Conselho Nacional de Desenvolvimento Científico e Tecnológico (CAPES/CNPq), "Science without Borders" Program through the project "Plant interactions and community dynamics in tropical, seasonal systems" (grant ref. UFSC 114A-2013). HT acknowledges 
27 financial support of the University of Potsdam through the Promos scholarship of the

28 Deutscher Akademischer Austauschdienst (DAAD). FIP was recipient of a Pesquisador

29 Visitante Especial grant (CAPES/CNPq), and the support is gratefully acknowledged. 
1 Seed germination and seedling establishment of an invasive tropical tree species under

2 different climate change scenarios

3

4

Increasing air temperature and atmospheric $\mathrm{CO}_{2}$ levels may affect the distribution of invasive species. Whereas we have wide knowledge on the effect of global change on temperate species, responses of tropical invasive species to these two global change drivers is largely

unknown. We used Terminalia catappa L. (Combretaceae), an invasive tree species in Brazilian coastal areas, to address the effects of increased air temperature and $\mathrm{CO}_{2}$ concentration on seed germination and seedling growth in a greenhouse experiment in the Santa Catarina island (Florianópolis, Brazil). Seeds of the invasive tree species were subject to two temperature levels (ambient and $+1.6^{\circ} \mathrm{C}$ ) and two $\mathrm{CO}_{2}$ levels (ambient and $\sim 650 \mathrm{ppm}$ ) with a factorial design. Increased temperature enhanced germination rate and shortened germination time of T. catappa seeds. It also increased plant height, number of leaves and aboveground biomass. By contrast, increased atmospheric $\mathrm{CO}_{2}$ concentration had no significant effects, and the interaction between temperature and $\mathrm{CO}_{2}$ concentration did not affect any measured trait. Terminalia catappa adapts to a relatively broad range of environmental conditions, being able to tolerate cooler temperatures in its invasive range. Global warming might favour the establishment of T. catappa, a native to warmer tropical regions, in South America coastal areas, while increased $\mathrm{CO}_{2}$ levels seem not to have significant effects on seed germination and seedling growth.

Keywords: $\mathrm{CO}_{2}$ concentration; coastal dunes; establishment; invasive plant; plant invasion; temperature; Terminalia catappa 


\section{Introduction}

Climate change and biological invasions are expected to strongly affect biodiversity and ecosystem services worldwide (Schröter et al. 2005; Cardinale et al. 2012). Changes in climate may, through several mechanisms, decrease ecosystem resistance to invasive species and enhance population growth of non-native species. For instance, environmental changes can ease non-native species spread if native species are less competitive, in terms of resource acquisition or in their ability to cope with biotic and abiotic stress factors (Qaderi et al. 2013, Manea et al. 2016). Although it is important to consider biological invasions in the light of climate change (Hellmann et al. 2008; Walther et al. 2009; Bradley et al. 2010) manipulative experiments have only occasionally addressed synergies among global change drivers (but see Jia et al. 2016; Johnson \& Hartley 2018). This may be especially the case of invasive species from tropical regions introduced to subtropical and temperate regions (Walther et al. 2009; Sheppard et al. 2014). Not surprisingly, our knowledge on invasion risk of tropical areas by alien tropical invaders is still scarce (Ackermann et al. 2017).

Several reports addressed the impact of increasing atmospheric $\mathrm{CO}_{2}$ on the performance of invasive plant species compared to their native neighbors. Most of them reported an increase in biomass (Dukes 2002; Hättenschwiler \& Körner 2003; Song et al. 2009) and height (Smith et al. 2000) of invasive species in the introduced range in response to higher $\mathrm{CO}_{2}$ concentrations. The analyzed invasive species included growth forms ranging from annual grasses (Smith et al. 2000; Nagel et al. 2004), to shrubs (Hättenschwiler \& Körner 2003; Belote et al. 2004), forbs (Dukes 2002) or perennial vines (Song et al. 2009). Evidence suggests that invasive plant species would overall benefit from higher atmospheric $\mathrm{CO}_{2}$ levels (Bradley et al. 2010; Loveys et al. 2010) perhaps because of higher gas exchange efficiency (Anderson \& Cipollini 2013; de Faria et al. 2018).

Most expectations about the effect of increasing temperature on plant invaders are based on habitat-suitability models (Kriticos et al. 2003; Beaumont et al. 2009; McDonald et al. 
2009; Bradley et al. 2010; Bellard et al. 2018). Lacking field manipulations, greenhouse experiments have shown that warming enhances seed germination and seedling growth of different invasive species (Hou et al. 2014; Skálová et al. 2015; Wang et al. 2011), although there are reports of negative impacts of global warming on germination and seedling establishment in temperate regions (e.g., Footitt et al. 2018). The impacts of global warming on seed and seedling responses have been relatively little addressed (Parmesan \& Hanley 2015), despite being critical phases which often suffer high mortality rates. These two critical, early life-history stages constitute the first hurdles of invasion success (Dechoum et al. 2015; Hirsch et al. 2016) in an otherwise complex process subject to multiple influences (Zenni et al. 2017).

Some reports have shown that elevated $\mathrm{CO}_{2}$ levels enhance the effects of higher temperatures, increasing plant growth and biomass (e.g., Qaderi et al. 2013; de Faria et al. 2018), but evidence is scant and points that it may not be always the case (e.g., Hely \& Roxburgh 2005). For instance, Sheppard and Stanley (2014) simulated current conditions and conditions projected for the end of the century using environmental chambers under the combination of two temperature $\left(23.7^{\circ}\right.$ and $\left.26^{\circ} \mathrm{C}\right)$ and two $\mathrm{CO} 2(450$ and $900 \mathrm{ppmv})$ regimes, assessing the effects for seedling growth of three woody invasive species in New Zealand. They showed that a significant interactive effect of elevated temperature and doubled $\mathrm{CO}_{2}$ was observed only for the relative growth rate of the height of one of the species, without any effects for the other two species or for other parameters such as total biomass and total leaf area. As a matter of fact, although non-native plants of tropical and subtropical origin introduced to colder regions are expected to increase the number and size of their populations and spread farther with climate change (Sheppard \& Stanley 2014), evidence shows that the success of these invasions are species- and context-dependent (Walther et al. 2009). 
Coastal sand dunes are the most invaded habitats in Europe (Chytrý et al. 2008), and highly susceptible to invasions worldwide (Campos et al. 2004; Defeo et al. 2009; Carboni et al. 2010; Barbosa et al. 2017) since they experience frequent disturbances and strong environmental stress (Castillo \& Moreno-Casasola 1996; Davis et al. 2000). Island coastal communities are threatened by changes in climate (Harley et al. 2006) but, overall, by extreme weather events (Burgiel \& Muir 2010) which remove large amounts of standing plant biomass and decrease the resistance of native communities to the establishment of invaders by decreasing the competitive ability of native species (Diez et al. 2012). In addition, urbanization processes and tourism expansion over coastal areas facilitate the introduction of alien species, mostly ornamentals (Alston \& Richardson 2006).

One expanding alien species in a coastal environment is Terminalia catappa L. (Combretaceae), a tree species native to Malaysia where average annual temperature is $27^{\circ} \mathrm{C}$ (Tang 2012). This species is invasive in Brazil, especially in coastal ecosystems, with Florianópolis (Santa Catarina, Brazil) being so far the southernmost point of occurrence (I3N Brazil 2017). It is worth note that mean annual temperature in Florianópolis $\left(20.3^{\circ} \mathrm{C}\right)$ is some $7^{\circ} \mathrm{C}$ lower than the native range of the species (EMBRAPA 2017).

Evaluating the effects of elevated $\mathrm{CO}_{2}$ at different life cycle stages is important to better understand its effects on whole-plant performance in natural ecosystems. With this purpose, we carried out a greenhouse experiment to assess the synergistic effects of increased air temperature and $\mathrm{CO}_{2}$ concentration on seed germination and seedling growth of the invasive tree species Terminalia catappa. Considering temperature differences between $T$. catappa native range and southern Brazil, and the potential effects of elevated $\mathrm{CO}_{2}$ on plant growth, we hypothesized that 1) warming, as a single factor, would enhance germination rate of T. catappa seeds; and 2) similarly, T. catappa seedlings would show higher growth rate under increased levels of atmospheric $\mathrm{CO}_{2}$. Finally, we expected 3) a synergistic effect 
between temperature and $\mathrm{CO}_{2}$ increases that would enhance $T$. catappa germination and seedling growth.

\section{Methods}

\section{Experimental design}

In a greenhouse experiment with a factorial design, we assessed the effects of increased air temperature and $\mathrm{CO}_{2}$ concentration on seed germination and seedling growth of T. catappa. We established two levels for each of the two factors; increased $(\mathrm{T}+)$ and ambient temperature (T-); and increased $(\mathrm{C}+)$ and ambient $\mathrm{CO}_{2}(\mathrm{C}-)$. Therefore, we had four treatments: control (T-C-), increased air temperature and ambient $\mathrm{CO}_{2}$ concentration $(\mathrm{T}+\mathrm{C}-)$, ambient air temperature and increased $\mathrm{CO}_{2}$ concentration $(\mathrm{T}-\mathrm{C}+)$, and increased air temperature and increased $\mathrm{CO}_{2}$ concentration $(\mathrm{T}+\mathrm{C}+)$. Our target was to increase temperature, on average, by $1.6^{\circ} \mathrm{C}$ and $\mathrm{CO}_{2}$ to $600-700 \mathrm{ppm}$, as expected for year 2100 (IPCC 2013;

Magrin et al. 2014). The experiment was carried out in a greenhouse at the Federal University of Santa Catarina (Florianópolis, southern Brazil) for 13 weeks between February and May 2016.

The experiment consisted of eight blocks, each including one replicate of each treatment (Fig. 1). Each experimental unit consisted of a plastic tray $(30 \mathrm{x} 45 \mathrm{~cm})$ placed inside an acrylic chamber (AC; Fig. 1) used to increase air temperature. To increase $\mathrm{CO}_{2}$ concentration in chambers $(\mathrm{C}+$ treatments), we sealed ACs with transparent, self-adhesive film, leaving open only the tray bottom to allow percolation of excess water. Chambers in $\mathrm{CO}_{2}$ control treatments $(\mathrm{C}-)$ were also sealed to avoid experimental artifacts. As ACs increased air temperature in all experimental units, we had to cool down half the ACs to achieve ambient temperature in 'control' treatments (T-). For this purpose, we set up an air conditioning system using a split air conditioner and PVC tubes isolated with thermal 
blankets to cool off half the chambers. The other half was supplied with ambient air from outside the greenhouse through a piping system connected to a forced ventilation device. $\mathrm{CO}_{2}$ concentration was maintained in $\mathrm{C}+$ treatments at $\sim 600-700 \mathrm{ppm}$ (Table 1 ) using gas cylinders. An infrared sensor (LI-COR Biosciences, Lincoln, NE, USA) connected to the tank controlled the amount of gas released. Each experimental chamber was an independent, closed system with an entrance of fresh air (cooled or not), and half of them had an additional entrance for $\mathrm{CO}_{2}$-enriched air (Appendix 1).

Fruits of T. catappa were collected at the Florianópolis coast at the end of autumn/early winter 2015 (June-August) and kept at $6^{\circ} \mathrm{C}$ until the start of the experiment. We removed the endocarp to improve germination (Sanches 2009). Seeds were then sterilized in a $75 \%$ ethanol solution for two minutes, to avoid fungal infection. Six T. catappa seeds were sown in each tray, which were filled with vermiculite. Trays were watered frequently (aprox. every 4 days), whenever vermiculite started to dry. Trays with increased air temperature $(\mathrm{T}+)$ were supplied $\sim 450 \mathrm{ml}$ and trays at ambient air temperature (T-) with $\sim 650 \mathrm{ml}$. The difference in watering was needed to account for the dehydrating effect of cooling by air conditioning, which could not be avoided.

\section{Data collection}

Temperatures were recorded hourly with iButton data loggers (Maxim Integrated, San Jose, CA, USA) installed in the inner side of each chamber. $\mathrm{CO}_{2}$ concentration in chambers was checked periodically with a portable IR sensor to maintain a value of $600-700 \mathrm{ppm}$ in $\mathrm{C}+$ treatments.

Seed germination of T. catappa was recorded daily in all chambers. Seedling growth was measured weekly for a period of five weeks before harvest. All plants that germinated after the $8^{\text {th }}$ week of the experiment were not considered for growth parameters but just recorded for seed germination analysis. 

recorded for each alive T. catappa individual at the end of the experiment $(\mathrm{n}=76)$. Specific leaf area (SLA) was determined by standard methods (Pérez-Harguindeguy et al. 2013). All leaves of each seedling were harvested, labelled and weighed with a precision scale. Then, each leaf was digitized with a scanner, oven-dried in paper bags at $72^{\circ} \mathrm{C}$ for $48 \mathrm{~h}$, and weighted. The projected areas of the scans were measured using Midebmp software (EEZA, Almería, Spain) and SLA was determined for each single leaf as a ratio between leaf area and dry mass. Mean SLA values were averaged for each seedling. The same procedure was followed in determining leaf dry matter content (LDMC). Above- and belowground plant parts were sorted out after harvest, oven-dried at $72^{\circ} \mathrm{C}$ for $48 \mathrm{~h}$, and weighed with a precision balance to obtain dry mass. Data of seedlings in a chamber were averaged prior to statistical analyses.

\section{Statistical analyses}

Records of $\mathrm{CO}_{2}$ concentration and air temperature were averaged for each chamber.

Wilcoxon test was used to compare air temperature between $\mathrm{T}+$ and $\mathrm{T}$ - treatments, while $\mathrm{t}$ test was used to test for differences in $\mathrm{CO}_{2}$ concentration between $\mathrm{C}+$ and $\mathrm{C}$ - treatments. The velocity of germination coefficient was calculated for each tray following Kader (2005). as performance estimators (plant height, number of leaves, above and belowground dry mass, SLA and LDMC) were analyzed with linear mixed-effect models (GLMM) considering air temperature, $\mathrm{CO}_{2}$ concentration and the interaction between them as fixed factors. Blocks were considered a random factor. Seedlings without leaves were not included in the models for SLA and LDMC $(n=62)$. All statistical analyses were performed with the software $\mathrm{R}$ version 3.0.3 (R Core Team 2014), using the package "lme4" (Bates et al. 2014) for the 


\section{Results}

Chambers significantly increased air temperature $(\mathrm{W}=12, \mathrm{p}<0.001)$, and $\mathrm{T}+$

182

183

184

185

186

187

188

189

190

191

192

193

194

195

196

197

198

199

200

201

202

203

treatments were on average $1.6^{\circ} \mathrm{C}$ warmer during daylight time than $\mathrm{T}$ - treatments (Table 1 ), but temperatures at night were similar. $\mathrm{CO}_{2}$-enriched chambers $(\mathrm{C}+)$ had on average $\sim 50 \%$ higher $\mathrm{CO}_{2}$ concentration than ambient $\mathrm{CO}_{2}(\mathrm{C}-)$ chambers $(\mathrm{t}=13.1$, d.f. $=16, \mathrm{p}<0.001$, Table 1).

Seed germination started 11 days after sowing. A total of 105 seeds germinated during the experiment, or $55 \%$ of the total seeds sown. In the $\mathrm{T}+\mathrm{C}+$ treatment, $68.8 \%$ of seeds germinated along the course of the experiment, compared with $62.5 \%$ in $\mathrm{T}+\mathrm{C}-, 47.9 \%$ in $\mathrm{T}$ C + and $39.6 \%$ in T-C-. Hence, seeds of T. catappa germinated notably faster in chambers with increased temperature $(\mathrm{Z}=2.23, \mathrm{p}<0.05)$. By contrast, neither $\mathrm{CO}_{2}$ increases nor the interaction $\mathrm{CO}_{2} \mathrm{x}$ temperature did have any effect $\left(\mathrm{Z}=0.82, \mathrm{p}=0.41\right.$ for $\mathrm{CO}_{2}$ and $\mathrm{Z}=0.10$, $\mathrm{p}$ $=0.92$, respectively; AIC: 118.7 , Fig. 2) pointing that all differences were due to temperature. In chambers with ambient temperature (T-C+ and T-C-) germination started three weeks later (Fig. 3) but $\mathrm{CO}_{2}$ had no effect $(\mathrm{t}=0.33, \mathrm{p}=0.74)$ and the non-significant $\mathrm{T} \times \mathrm{CO}_{2}$ interaction again suggest all differences were due to temperature $(t=0.44, p=0.66$; AIC: 172.3 , Fig. 3). Temperature did also affect plant growth and allocation patterns, increasing plant height, number of leaves, and aboveground biomass (Table 2). It also led to a decrease in the root-to-shoot ratio, showing that warmed plants allocated less biomass to roots. Warming, however, had no effect on total biomass, SLA or LDMC (Table 2). Contrary to our expectations, $\mathrm{CO}_{2}$ concentration did not have any effect on any seedling trait we measured (Table 2).

\section{Discussion}


Increased temperature had positive effects on T. catappa seed germination and seedling growth, while increased $\mathrm{CO}_{2}$ concentration had no effects. Therefore, our hypotheses were supported just in part. Our results showed that even a small rise in daytime temperature $\left(1.6^{\circ} \mathrm{C}\right)$ was enough to enhance T. catappa seed germination rate. Pearson et al. (2002) reported that some tropical pioneer species, especially those with larger seeds, increased germination rate with increasing temperature most likely due to its effects on seed coat permeability (Baskin \& Baskin 1998).

Contrary to our expectations, T. catappa seedlings did not respond to increased $\mathrm{CO}_{2}$

levels, neither in terms of growth (height, biomass, number of leaves) or functional traits (root/shoot, SLA, LDMC). These results are not surprising since similar outcomes have been reported elsewhere (Tooth \& Leishman 2014; Manea et al. 2016). However, controversial results and predictions have been published showing a better performance of invasive species when compared to native species under elevated $\mathrm{CO}_{2}$ levels (Raizada et al. 2009; Bradley et al. 2010; Liu et al. 2017), increasing the spread of invasive plant species.

The lack of responses to increased $\mathrm{CO}_{2}$ in our species could be due to the short-term focus of our experimental design, which may have not been long enough to induce responses. Norby et al. (1992) found that growth efficiency (aboveground mass per unit leaf area) increased only after two years of $\mathrm{CO}_{2}$ enrichment. Similarly, Hättenschwiler and Körner (2003) reported that increased $\mathrm{CO}_{2}$ levels enhanced biomass production after three growing seasons in Prunus laurocerasus, an invasive shrub in temperate forests. In addition, increased water use efficiency is one potential benefit of elevated $\mathrm{CO}_{2}$ (Allen Jr et al. 2011; Cheng et al. 2017). However, this potential benefit was largely eliminated by the watering regime, one possible reason that a $\mathrm{CO}_{2}$ effect was not observed. scantly addressed in the scientific literature, and evidence is not strong enough to draw 
positive effect of single factors on invasive herb species, as experimental warming may counter any positive impacts of increased $\mathrm{CO}_{2}$ alone (Williams et al. 2007; Van de Velde et al. 2015). However, Liu et al. (2017) reported that elevated temperature and $\mathrm{CO}_{2}$ enrichment increased the performance of invasive alien plant species more strongly than of native species. In other experiments, the combined effects of increased temperature and high $\mathrm{CO}_{2}$ provided inconsistent results, suggesting that it is highly species-specific and context-dependent (Bradley et al. 2010; Huang 2016).

Terminalia catappa seedlings showed high phenotypic variability expressed through functional traits in response to temperature increases. This suggests high range of tolerance to temperature especially during early developmental stages, when the plant is most vulnerable. However, it is not clear how adult individuals of T. catappa will respond to these environmental changes and whether this variability is adaptive (resulting in greater fitness). As there are no native congeners to the invasive $T$. catappa, we cannot test whether $T$. catappa has a higher variability/plasticity than related native species. It is worth mentioning, though, that most studies addressing plasticity focused on species responses to resource availability and light (e.g., Funk 2008; Davidson et al. 2011; Godoy et al. 2011; PalacioLópez \& Gianoli 2011), and temperature has been somehow neglected in this context, which makes it difficult to put our results in a wider context.

In conclusion, our data show that establishment of the invasive tree species, Terminalia catappa, will probably be favored in coastal dunes of southern Brazil, since seed germination and seedling growth were enhanced under increased air temperature. Terminalia catappa is able to adapt to a relatively broad range of environmental conditions tolerating cooler temperatures in the invasive range. With ongoing global warming trends, T. catappa is expected to establish and spread into new areas. Thus, it is critical to identify areas susceptible to invasion, with particular attention to protected areas, and adopt appropriate control actions. In addition, local regulations should be enforced to prevent the use of the 
species for ornamental purposes both in private and public properties. Actions should include the species control and eradication when possible in coastal areas to reduce propagule arrival in relevant sites for biological conservation.

\section{References}

Ackerman, JD; RL Tremblay; J Rojas-Sandoval; E Hernandez-Figueroa. 2017. Biotic resistance in the tropics: patterns of seed plant invasions within an island. Biol Invasions 19:315-328

Allen, LH, Jr; VG Kakani; JC Vu; KJ Boote. 2011. Elevated CO2 increases water use efficiency by sustaining photosynthesis of water-limited maize and sorghum. J Plant Physil 168(16):1909-18

Alston, KP \& DM Richardson. 2006. The roles of habitat features, disturbance, and distance from putative source populations in structuring alien plant invasions at the urban/wildland interface on the Cape Peninsula, South Africa. Biol Conserv 132:183-198

Anderson, LJ \& D Cipollini. 2013. Gas exchange, growth, and defense responses of invasive Alliaria petiolata (Brassicaceae) and native Geum vernum (Rosaceae) to elevated atmospheric $\mathrm{CO} 2$ and warm spring temperatures. Am J Bot 100:1544-1554

Barbosa, C; MS Dechoum; TT Castellani. 2017. Population structure and growth of a non native invasive clonal plant on coastal dunes in Southern Brazil. Neotrop Biol Conserv 12:214-223

Baskin, CC \& JM Baskin. 1998. Seeds: Ecology, biogeography, and evolution of dormancy and germination. Academic Press [San Diego, USA. 666 pp.]

Bates, D; M Maechler; B Bolker; S Walker. 2014. lme4: Linear mixed-effects models using Eigen and S4. R package version 1.1-7. http://CRAN.R-project.org/package=lme4. Accessed 16 November 2016 
Beaumont, LJ; RV Gallagher; W Thuiller; PO Downey; MR Leishman et al. 2009. Different climatic envelopes among invasive populations may lead to underestimations of current and future biological invasions. Divers Distrib 15:409-420

Bellard, C; JM Jeschke; B Leroy; GM Mace. 2018. Insights from modeling studies on how climate change affects invasive alien species geography. Ecol Evol 8:5688-5700

Belote, RT; JF Weltzin; RJ Norby. 2004. Response of an understory plant community to elevated [CO2] depends on differential responses of dominant invasive species and is mediated by soil water availability. New Phytol 161:827-835

Bradley, BA; DM Blumenthal; DS Wilcove; LH Ziska. 2010. Predicting plant invasion in an era of global change. Trends Ecol Evol 25:310-318

Burgiel, SW \& AA Muir. 2010. Invasive Species, Climate Change and Ecosystem-Based Adaptation: Addressing Multiple Drivers of Global Change. Global Invasive Species Programme (GISP) [Washington DC, USA \& Nairobi, Kenya]

Campos, JA; M Herrera; I Biurrun; J Loidi. 2004. The role of alien plants in the natural coastal vegetation in central-northern Spain. Biodiv Conserv 13:2275-2293

Carboni, M; R Santoro; ATR Acosta. 2010. Are some communities of the coastal dune zonation more susceptible to alien plant invasion? J Plant Ecol 3:139-147

Cardinale, BJ; JE Duffy; A Gonzalez; DU Hooper; P Charles et al. 2012. Biodiversity loss and its impact on humanity. Nat 486:59-67

Castillo, SA \& P Moreno-Casasola. 1996. Coastal sand dune vegetation: An extreme case of species invasion. J Coast Conserv 2:13-22

Cheng, L; L Zhang; Y-P Wang; JG Canadell; FHS Chiew et al. 2017. Recent increases in terrestrial carbon uptake at little cost to the water cycle. Nat Comm $\mathbf{8}$

Chytrý, M; LC Maskell; J Pino; P Pysek; M Villa et al. 2008. Habitat invasions by alien plants: A quantitative comparison among mediterranean, subcontinental and oceanic regions of Europe. J Appl Ecol 45:448-458 
Davidson, AM; M Jennions; AB Nicotra. 2011. Do invasive species show higher phenotypic plasticity than native species and, if so, is it adaptive? A meta-analysis. Ecol Lett 14:419431

Davis, MA; JP Grime; K Thompson. 2000. Fluctuating resources in plant communities: A general theory of invasibility. $J$ Ecol 88:528-534

Dechoum, MS; RD Zenni; TT Castellani; SM Zalba; M Rejmánek. 2015. Invasions across secondary forest successional stages: effects of local plant community, soil, litter, and herbivory on Hovenia dulcis seed germination and seedling establishment. Plant Ecol

Diez, JM; CM D'Antonio; JS Dukes; ED Grosholz; JD Olden et al. 2012. Will extreme 216: $823-833$

Defeo, O; A McLachlan; DS Schoeman; TA Schlacher; J Dugan et al. 2009. Threats to sandy beach ecosystems: A review. Estuar Coast Shelf Sci 81:1-12
climatic events facilitate biological invasions? Front Ecol Environ 10:249-257

Dukes, JS. 2002. Comparison of the effect of elevated CO2 on an invasive species (Centaurea solstitialis) in monoculture and community settings. Plant Ecol 160:225-234

EMBRAPA - Empresa brasileira de pesquisa agropecuária. 2017. Banco de dados climáticos do Brasil.

https://www.cnpm.embrapa.br/projetos/bdclima/balanco/resultados/sc/231/balanco.html. Accessed 15 March 2017

de Faria, AP; MA Marabesi; M Gaspar; MGC Franca. 2018. The increase of current atmospheric $\mathrm{CO} 2$ and temperature can benefit leaf gas exchanges, carbohydrate content and growth in C4 grass invaders of the Cerrado biome. Plant Physiol Biochem 127:608616

Footitt, S; Z Huang; H Olcer-Footitt; H Clay; WE Finch-Savage. 2018. The impact of global warming on germination and seedling emergence in Alliaria petiolata, a woodland species with dormancy loss dependent on low temperature. Plant Biol 20:682-690 
Funk, JL. 2008. Differences in p 381 lasticity between invasive and native plants from a low resource environment. $J$ Ecol 96:1162-1173

Godoy, O; F Valladares; P Castro-Diez. 2011. Multispecies comparison reveals that invasive and native plants differ in their traits but not in their plasticity. Funct Ecol 25:1248-1259

Harley, CDG; AR Hughes; KM Hultgren; BG Miner; CJB Sorte et al. 2006. The impacts of climate change in costal marine systems. Ecol Lett 8:228-241

Hättenschwiler, S; C Körner. 2003. Does elevated CO2 facilitate naturalization of the non indigenous Prunus laurocerasus in Swiss temperate forests? Funct Ecol 17:778-785

Hellmann, JJ; JE Byers; BG Bierwagen; JS Dukes. 2008. Five potential consequences of climate change for invasive species. Conserv Biol 22:534-543

Hely, SEL; SH Roxburgh. 2005. The interactive effects of elevated CO2, temperature and initial size on growth and competition between a native $\mathrm{C} 3$ and an invasive $\mathrm{C} 3$ grass.

\section{Plant Ecol 177:85-98}

Hirsch, H; I Hensen; K Wesche; D Renison; C Wypior et al. 2016. Non-native populations of an invasive tree outperform their native conspecifics. AoB Plant 8:plw071

Hou, QQ; BM Chen; SL Peng; LY Chen. 2014. Effects of extreme temperature on seedling establishment of nonnative invasive plants. Biol Invasions 16:2049-2061

Huang, G. 2016. Differential response to climate change among populations for woody plant species: An ecological and physiological approach. $\mathrm{PhD}$ thesis, Western Sydney University [Australia]

I3N Brazil. 2017. National database on invasive alien species - I3N Brasil. http://i3n.institutohorus.org.br. Accessed 01 February 2017

IPCC. 2013. Climate Change 2013: The Physical Science Basis. Contribution of Working Group I to the Fifth Assessment Report of the Intergovernmental Panel on Climate Change in: TF Stocker; D Qin; G-K Plattner; M Tignor; SK Allen et al. (eds). Cambridge University Press [Cambridge, United Kingdom \& New York, USA. 1585 pp.] 
Jia, JJ; ZC Dai; F Li; YJ Liu. 2016. How will global environmental changes affect the growth of alien plants? Front Plant Sci 7:1623

Johnson, SN; SE Hartley. 2018. Elevated carbon dioxide and warming impact silicon and phenolic-based defences differently in native and exotic grasses. Glob Change Biol 24: 3886-3896

Kader, MA. 2005. A comparison of seed germination and calculation formulae and the associated interpretation of resulting data. J Proc R Soc New South Wales 138:65-75

Kriticos, DL; RW Sutherst; JR Brown; SW Adkins; GF Maywald. 2003. Climate change and the potential distribution of an invasive alien plant: Acacia nilotica ssp. indica in Australia. J Appl Ecol 40:111-124

Liu, YJ; AMO Oduor; Z Zhang; A Manea; IM Tooth et al. 2017. Do invasive alien plants benefit more from global environmental change than native plants? Global Change Biol 23:3363-3370

Loveys, BR; JJG Egerton; D Bruhn; MC Ball. 2010. Disturbance is required for $\mathrm{CO}_{2^{-}}$ dependent promotion of woody plant growth in grasslands. Funct Plant Biol 37:555-565 Magrin, GO; JA Marengo; J-P Boulanger; MS Buckeridge; E Castellanos et al. 2014. Central and South America. [27] Pp. 1499-1566 in: VR Barros; CB Field; DL Dokken; MD Mastrandrea; KL Mach et al. (eds). Climate Change 2014: Impacts, Adaptation, and Vulnerability. Part B: Regional Aspects. Contribution of Working Group II to the Fifth Assessment Report of the Intergovernmental Panel on Climate Change. Cambridge University Press [Cambridge, USA. 1585 pp.]

Manea, A; DR Sloane; MR Leishman. 2016. Reductions in native grass biomass associated with drought facilitates the invasion of an exotic grass into a model grassland system. Oecol 181:175-183 
McDonald, A; S Riha; A Ditommaso; A Degaetane. 2009. Climate change and the geography of weed damage: Analysis of US maize systems suggest the potential for significant range transformations. Agric Ecosyst Environ 130:131-140

Morales, M. 2012. sciplot: Scientific 431 graphic functions for factorial designs. R package version 1.1-0. http://CRAN.R-projct.org/package=sciplot. Accessed 20 April 2017

Nagel, JM; TE Huxman; KL Griffin, SD Smith. 2004. CO2 enrichment reduces the energetic cost of biomass construction in an invasive desert grass. Ecol 85:100-106

Norby, RJ; CA Gunderson; SD Wullschleger; EG O’Neill; MK McCracken. 1992. Productivity and compensatory response of yellow poplar trees in elevated CO2. Nat 357:322-324

Palacio-López, K; E Gianoli. 2011. Invasive plants do not display greater phenotypic plasticity than their native or non-invasive counterparts: A meta-analysis. Oikos 120:1393- 1401

Parmesan, C; ME Hanley. 2015. Plants and climate change: complexities and surprises. Annals of Botany, 116:849-864

Pearson, TRH; DFRP Burslem; SE Mullins; JW Dalling. 2002. Germination ecology of neotropical pioneers: Interacting effects of environmental conditions and seed size. Ecol 83:2798-2807

Pérez-Harguindeguy, N; S Diaz; E Garnier; S Lavorel, H Poorter et al. 2013. New handbook for standardized measurement of plant functional traits worldwide. Aust J Bot 61:167-234

Qaderi, MM; AL Lynch; VJ Godin; DM Reid. 2013. Single and interactive effects of temperature, carbon dioxide and watering regime on invasive weed black knapweed (Centaurea nigra). Ecosciences 20:328-338

R Core Team. 2014. R: A language and environment for statistical computing. R Foundation for Statistical Computing. [Vienna] http://www.R-project.org/ 
Raizada, P; A Singh; AS Raghubanshi. 2009. Comparative response of seedlings of selected native dry tropical and alien invasive species to CO2 enrichment. J Plant Ecol 2(2):69-75

Sanches, JH. 2009. Potencial invasor do chapéu-de-sol (Terminalia catappa L.) em área de restinga. Master thesis, University of São Paulo [Brazil].

Schröter, D; W Cramer; R Leemans; IC Prentice; M-B Araújo et al. 2005. Ecosystem service supply and vulnerability to global change in Europe. Sci 310:1333-1337

Sheppard, CS; MC Stanley. 2014. Does elevated temperature and doubled CO2 increase growth of three potentially invasive plants? Invasive Plant Sci Manag 7: 237-246

Skálová, H; L Moravcová; AFG Dixon; P Kindlmann; P Pysek. 2015. Effect of temperature and nutrients on the growth and development of seedlings of an invasive plant. AoB Plant 7:plv074

Smith, SD; TE Huxman; SF Zitzer; TN Charlet; DC Housman et al. 2000. Elevated CO2 increases productivity and invasive species success in an arid ecosystem. Nat 408:79-82

Song, LY; J Wu; C Li; F Li;S Peng et al. 2009. Different responses of invasive and native species to elevated CO2 concentration. Acta Oecol 35:128-135

Tang, CK. 2012. Malaysia's weather data. Building energy efficiency technical guideline for passive design. [2] in: CK Tang; L Chin (eds). Building sector energy efficiency project. http://bseep.weebly.com/uploads/8/0/7/2/8072374/chapter_2__malaysia_weather_data_draft_01.pdf.

Tooth, IM; M Leishman. 2014. Elevated carbon dioxide and fire reduce biomass of native grass species when grown in competition with invasive exotic grasses in a savanna experimental system. Biol Invasions 16:257-268

Van de Velde, H; D Bonte; H Abdelgawad; H Asard; I Nijs. 2015. Combined elevated $\mathrm{CO}_{2}$ and climate warming induces effects of drought in Lolium perenne and Plantago lanceolata. Plant Ecol 216:1047-1059 
433 Walther, G-R; A Roques; PE Hulme; MT Sykes; P Pysek et al. 2009. Alien species in a $434 \quad$ warmer world: Risks and opportunities. Trends Ecol Evol 24:686-693

435 Wang, RL; RS Zeng; SL Peng; BM Chen; XT Liang et al. 2011. Elevated temperature may 436 accelerate invasive expansion of the liana plant Ipomoea cairica. Weed Res 51:574-580

437 Williams, AL; KE Wills; JK Janes; JK Vander Schoor, PCD Newton et al. 2007. Warming 438 free-air $\mathrm{CO}_{2}$ enrichment alter demographics in four co-occurring grassland species. New Phytol 176:365-374

440 Zenni, RD; IA Dickie; MJ Wingfield; H Hirsch; CJ Crous et al. 2017. Evolutionary dynamics 441 of tree invasions: Complementing the unified framework for biological invasions. $A o B$ Plant 9:plw085 
443 Table 1 Mean $( \pm \mathrm{SD})$ of air temperature and $\mathrm{CO}_{2}$ concentration in four treatments: $\mathrm{T}+\mathrm{C}+$ 444 (increased temperature and $\mathrm{CO}_{2}$ concentration), $\mathrm{T}+\mathrm{C}$ - (increased temperature and ambient $\mathrm{CO}_{2}$ 445 concentration), $\mathrm{T}-\mathrm{C}+\left(\right.$ ambient temperature and increased $\mathrm{CO}_{2}$ concentration) and T-C446 (control, ambient conditions).

\begin{tabular}{|c|c|c|c|}
\hline Variable & Level & Treatment & Mean \pm SD \\
\hline \multirow{4}{*}{ Air tempe } & $\mathrm{T}+$ & $\mathrm{T}+\mathrm{C}+$ & $25.4 \pm 0.53$ \\
\hline & & $\mathrm{T}+\mathrm{C}-$ & $25.1 \pm 0.84$ \\
\hline & & $\mathrm{T}-\mathrm{C}+$ & $23.8 \pm 1.12$ \\
\hline & & T-C- & $23.5 \pm 1.09$ \\
\hline \multirow{4}{*}{$\mathrm{CO}_{2}$ conce } & & $\mathrm{T}+\mathrm{C}+$ & $692 \pm 36$ \\
\hline & & $\mathrm{T}-\mathrm{C}+$ & $570 \pm 54$ \\
\hline & & $\mathrm{T}+\mathrm{C}-$ & $384 \pm 9$ \\
\hline & & T-C- & $360 \pm 8$ \\
\hline
\end{tabular}


Table 2 Morphological and functional traits (mean $\pm \mathrm{SD})$ of $T$. catappa seedlings in the four treatments: $\mathrm{T}+\mathrm{C}+\left(\right.$ increased temperature and $\left.\mathrm{CO}_{2}\right)$,

$\mathrm{T}+\mathrm{C}$ - (increased temperature and ambient $\left.\mathrm{CO}_{2}\right), \mathrm{T}-\mathrm{C}+\left(\right.$ ambient temperature and increased $\left.\mathrm{CO}_{2}\right)$ and T-C- (control, ambient conditions). $p$ values $(\mathrm{T}$

451 Information Criterion (AIC) of the GLMMs are also presented. Units for height is $\mathrm{cm}$, for biomass is $\mathrm{g}$, for SLA $\mathrm{m}^{2} / \mathrm{kg}$, and for LDMC $\mathrm{mg} / \mathrm{g}$.

452 Significant $p$ values are in bold.

\begin{tabular}{|c|c|c|c|c|c|c|c|}
\hline Treatment & Height & $\begin{array}{c}\text { Number of } \\
\text { leaves }\end{array}$ & Total biomass & $\begin{array}{c}\text { Total above-ground } \\
\text { biomass }\end{array}$ & Root-to-shoot ratio & SLA & LDMC \\
\hline $\mathbf{T}+\mathbf{C}-$ & $17.3 \pm 3.9$ & $2.8 \pm 1.3$ & $0.59 \pm 0.27$ & $0.51 \pm 0.20$ & $0.25 \pm 0.06$ & $34.7 \pm 1.01$ & $203 \pm 97$ \\
\hline T-C- & $8.8 \pm 3.2$ & $1.0 \pm 0.9$ & $0.45 \pm 0.16$ & $0.37 \pm 0.10$ & $0.32 \pm 0.06$ & $27.8 \pm 1.47$ & $175 \pm 87$ \\
\hline
\end{tabular}

\section{Statistics}

\begin{tabular}{lccccccc}
\hline $\mathbf{p}(\mathbf{T})$ & $<\mathbf{0 . 0 0 1}$ & $\mathbf{< 0 . 0 1}$ & 0.07 & $<\mathbf{0 . 0 5}$ & $<\mathbf{0 . 0 1}$ & 0.23 & 0.46 \\
$\mathbf{p}\left(\mathbf{C O}_{2}\right)$ & 0.29 & 0.67 & 0.54 & 0.55 & 0.95 & 0.60 & 0.27 \\
$\mathbf{p}\left(\mathbf{T} \times \mathbf{C O}_{2}\right)$ & 0.22 & 0.55 & 0.64 & 0.40 & 0.09 & 0.43
\end{tabular}


AIC

458.2

249.8

17.5

60.9

161

773.2

734

453

454 
Fig. 1 Experimental design of the greenhouse experiment. We used 32 chambers (1 chamber $=1$ tray with 6 T. catappa seeds) for 13 weeks combining increased air temperature (grey circles) and increased $\mathrm{CO}_{2}$ level (clear circles). This resulted in 8 blocks comprising four treatments: T-C- (control, ambient temperature and $\mathrm{CO}_{2}$ concentration); $\mathrm{T}-\mathrm{C}+\left(\right.$ ambient temperature and increased $\mathrm{CO}_{2}$ concentration); $\mathrm{T}+\mathrm{C}-$ (increased temperature and ambient $\mathrm{CO}_{2}$ concentration); and $\mathrm{T}+\mathrm{C}+($ increased temperature and $\mathrm{CO}_{2}$ concentration).

Fig. 2 Percentage of germination (mean $\pm \mathrm{SD}$ ) of Terminalia catappa seeds at a) ambient temperature $(\mathrm{T}-)$ and increased temperature $(\mathrm{T}+)$; and $\mathrm{b})$ ambient $\left(\mathrm{C}^{-}\right)$and increased $\mathrm{CO}_{2}(\mathrm{C}+)$ levels. Different letters mean significant differences in paired comparisons ( $\mathrm{T}$ - and $\mathrm{T}+$, and $\mathrm{C}$ - and $\mathrm{C}+$ ).

Fig. 3 Cumulative percentage of germination of Terminalia catappa seeds at ambient $(\mathrm{T}-)$ and increased $(\mathrm{T}+)$ temperature, and ambient $(\mathrm{C}-)$ and increased $(\mathrm{C}+) \mathrm{CO}_{2}$ levels. 


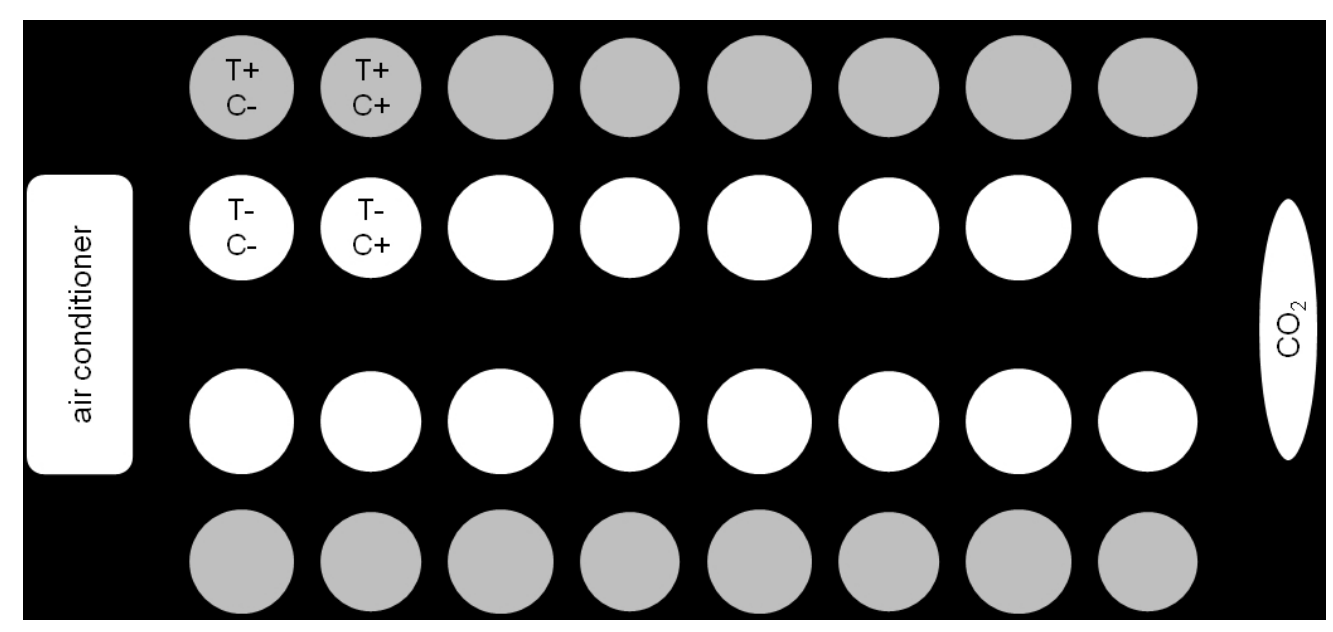

$175 \times 80 \mathrm{~mm}(150 \times 150 \mathrm{DPI})$ 

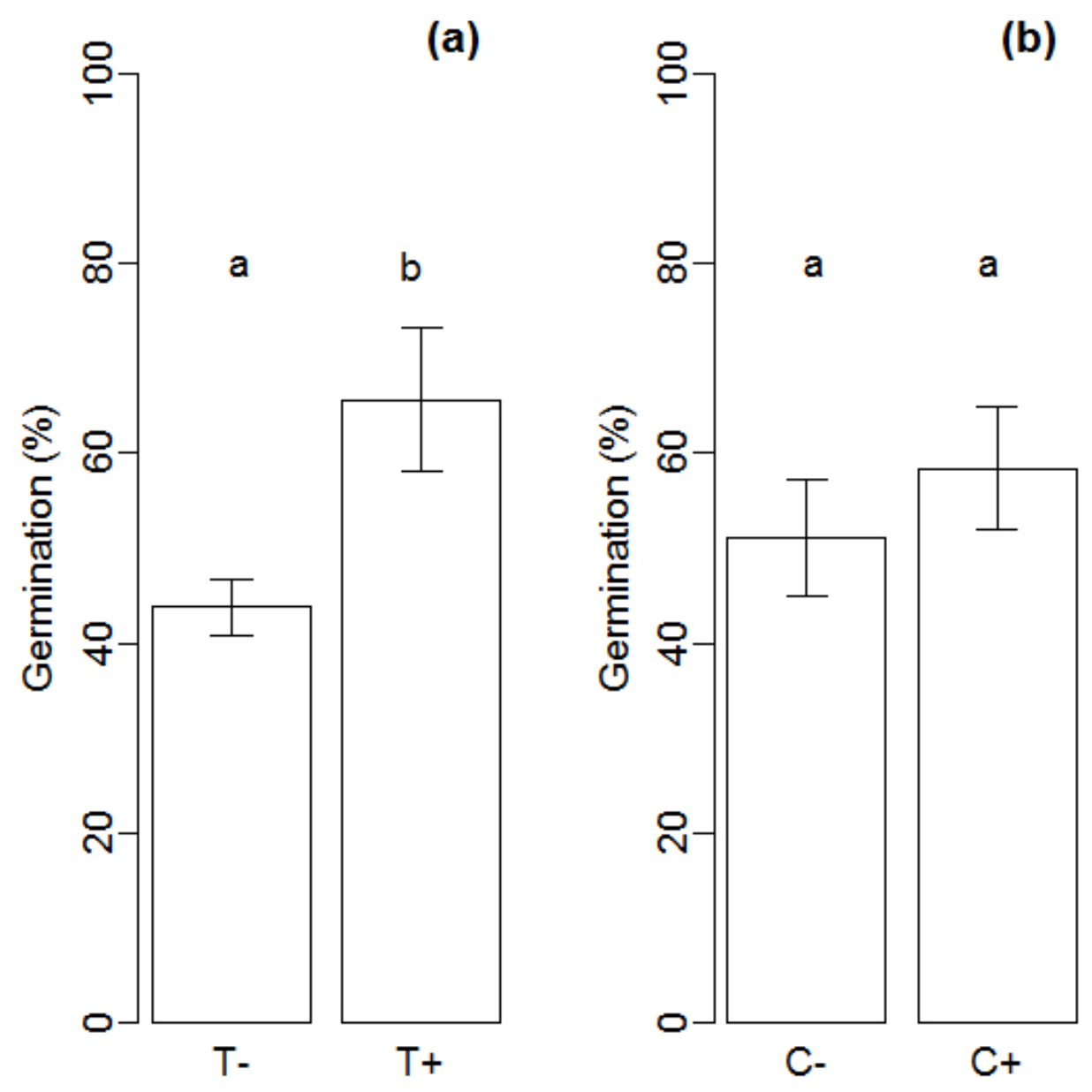

$195 \times 194 \mathrm{~mm}(72 \times 72$ DPI $)$ 


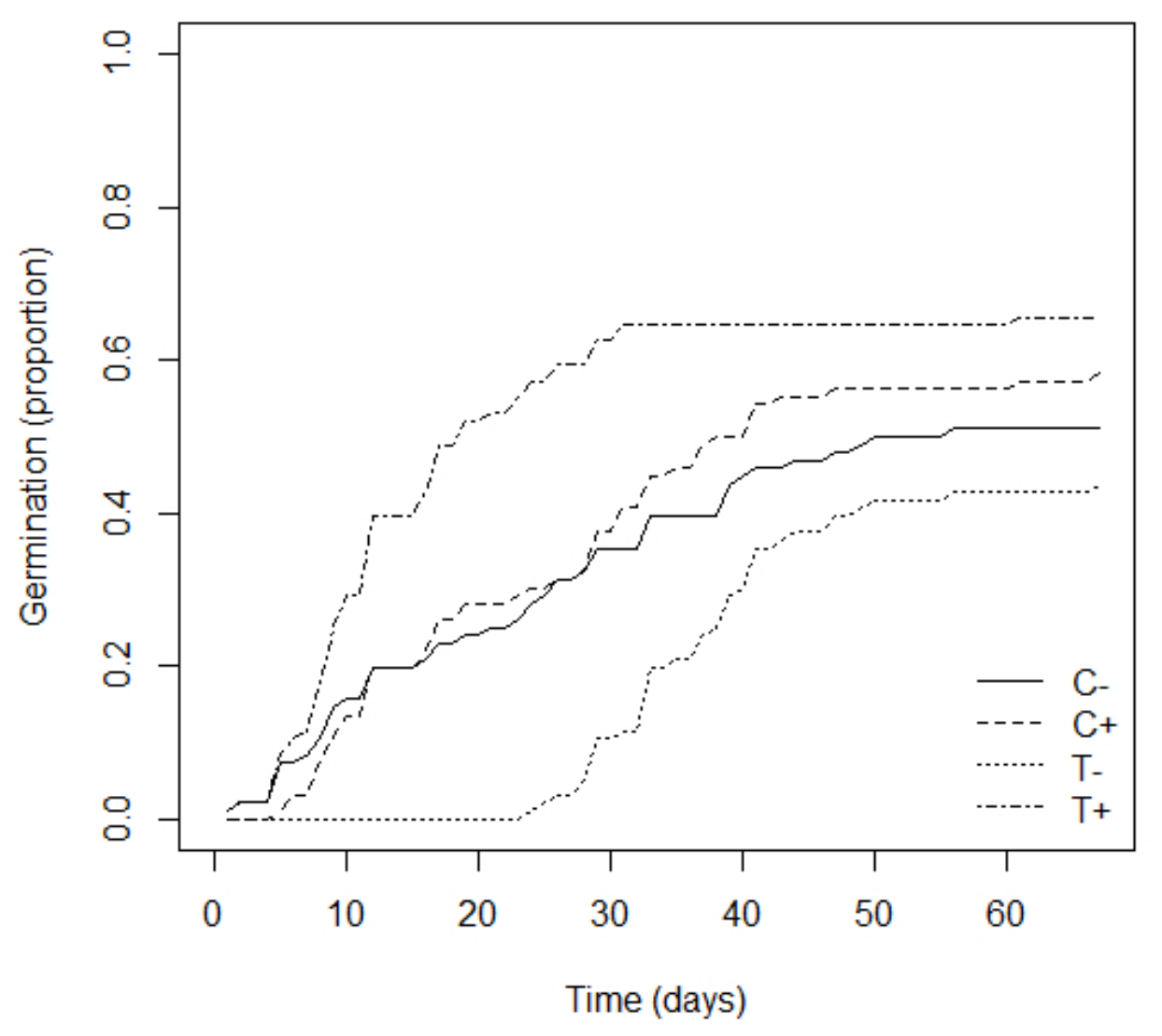

$195 \times 194 \mathrm{~mm}(72 \times 72$ DPI $)$ 


\section{Appendix 1}

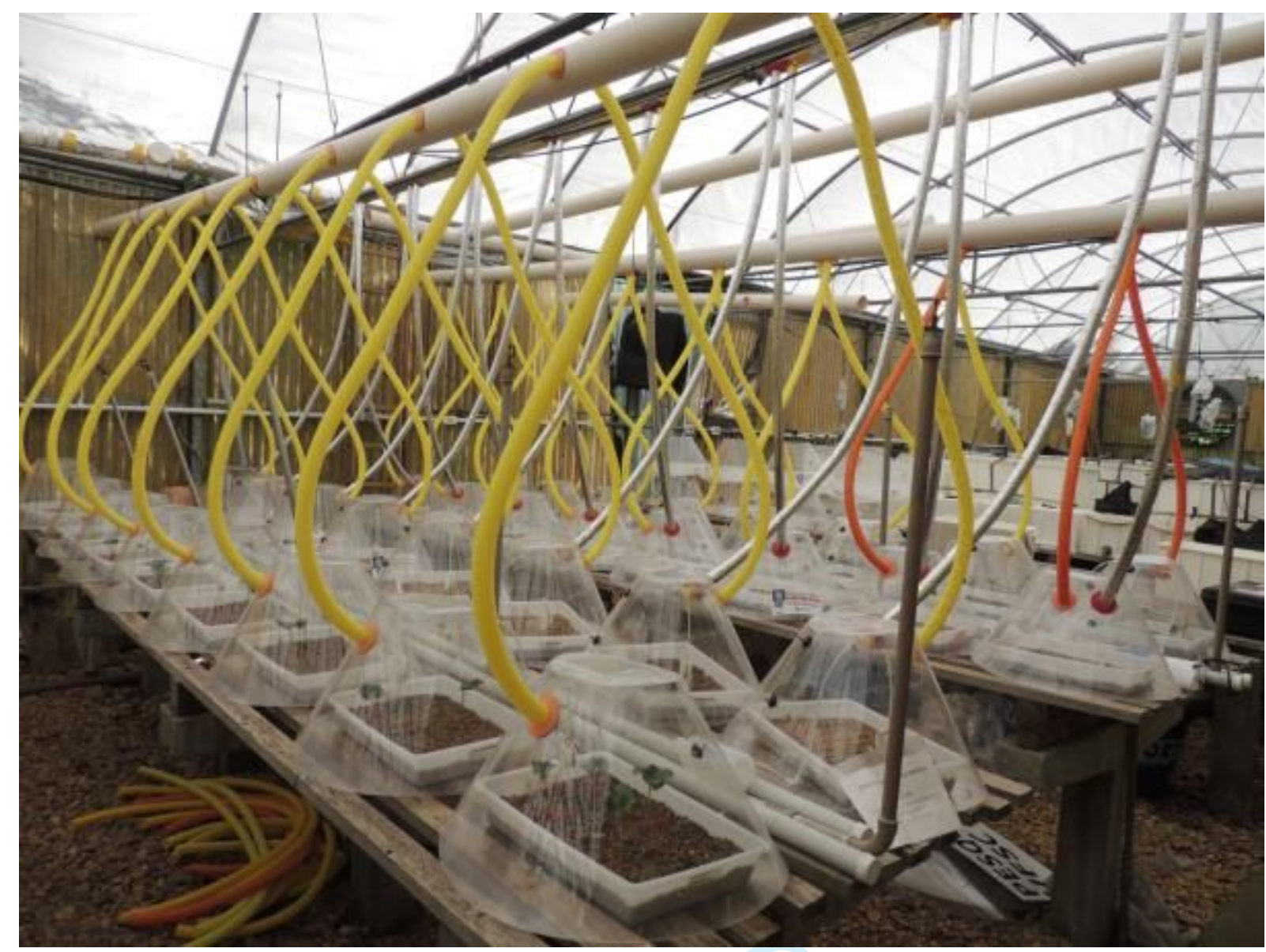

Picture of the experiment in the greenhouse, testing the effect of increases in temperature and

$\mathrm{CO}_{2}$ concentration on T. catappa seed and seedling. Experimental units (closed chambers with trays filled with vermiculite) were supplied with ambient air and/or $\mathrm{CO}_{2}$-enriched air (pipes in the middle of the bench), cooled air for ambient temperature provided by an air conditioner (silver isolated tubes) and with an output for air (yellow and orange tubes). $T$. catappa seeds were sown in the 32 closed chambers and seedlings were harvested after a growth period of six weeks. 